\title{
Oxidation Behavior and Caking Property of Coal under the Atmosphere at Low Oxygen Concentration
}

\author{
Hiroshi OTA, Takayuki TAKARADA, Yukihiko MAENO ${ }^{1)}$ and Masaru NISHIMURA ${ }^{2)}$ \\ Faculty of Engineering, Gunma University, Tenjin-cho, Kiryu, Gunma 376-8515 Japan. \\ 1) Nippon Steel Chemical Co., Ltd., Kimitsu, Kimitsu-shi, Chiba-ken 299-1196 Japan. \\ 2) Research and Development Center, The Kansai Coke and Chemicals Co., Ltd., Oh-Hama-cho, Amagasaki 660-0095 Japan.
}

(Received on September 4, 2002; accepted in final form on November 12, 2002)

\begin{abstract}
Eight coals ranging from bituminous coal to brown coal were oxidized in a thermo-balance or a fixed bed reactor using 5 vol\% of oxygen at $100-380^{\circ} \mathrm{C}$ for $10-400 \mathrm{~min}$. The effects of coal particle size, coal rank, oxidation temperature and oxygen concentration on the oxidation behavior of coal were investigated. The caking property, FT-IR spectrum and pyrolysis behavior of sample oxidized were measured. The oxidation behavior strongly depended on the coal rank. The oxidation reaction of highly caking coal was controlled by the rate of internal gaseous diffusion. The caking property of bituminous coal decreases by the oxidation in the oxidative atmosphere of low oxygen concentration of 5 vol\%, which corresponds to that in a flue gas.

The aliphatic $\mathrm{C}-\mathrm{H}$ groups in highly caking coals are easily oxidized during oxidation and remained in coal structure as relatively stable forms. The differences in chemical structure and caking property between the exterior part and the central part of oxidized coal particle was investigated. In the case of highly caking coal, the chemical structure and some properties of oxidized coal depends on the position of the coal particle because the mild oxidation reaction of coal proceeds from the exterior part of coal particle.
\end{abstract}

KEY WORDS: coal; oxidation; coal type; coking.

\section{Introduction}

It is well known that the atmospheric oxidation of coal influences the caking property of coal. ${ }^{1-4)}$ The process of coal oxidation has considerably been investigated ${ }^{5-8)}$ and kinetics of low temperature oxidation has been studied. Air including $\mathrm{O}_{2}$ of $21 \mathrm{vol} \%$ was used for oxidation experiments in many studies, because the purposes of those were on the weathering, spontaneous combustion and decaking by air pretreatment of caking coal.

Many studies on the mechanism at low temperature oxidation of coal were reported. Sanchez and Rincon ${ }^{1)}$ investigated the coal oxidation at temperatures around $125^{\circ} \mathrm{C}$ and they found the formation of peroxide, hydroperoxide, carbonyl and phenolic groups during the oxidation. These product species may serve as crosslinking precursor which causes decaking of caking coal. Gong et al. ${ }^{9}{ }^{9}$ examined the structural changes of the coal surface upon the oxidation treatment at $20-120^{\circ} \mathrm{C}$ with XPS and SIMS. They revealed that $\mathrm{C}-\mathrm{O}$ groups (hydroxyl group and ether linkages) were formed in the temperature range $20-120^{\circ} \mathrm{C}$ and in higher temperature around $100-120^{\circ} \mathrm{C}$, the formation of $\mathrm{C}=\mathrm{O}$ (carbonyl groups) was only observed at the beginning of oxidation, and then, $\mathrm{O}=\mathrm{C}-\mathrm{O}$ (carboxyl groups) was formed.

Recently, drying and preheating processes of coal have been developing in order to make high quality coke efficiently. From the practical point of view, it is desirable for the preheating of coal to use flue gas, that is, $\mathrm{O}_{2}$ of 4-5 vol\%. Although there are a number of studies on the coal oxidation and caking properties, quite limited informations on the oxidation behaviors and the effect of oxidation on the caking properties under the oxidation conditions of low oxygen concentrations have been reported.

In this study, the oxidation behaviors of coals from bituminous coal to brown coal were clarified using $5 \mathrm{vol} \%$ of oxygen. The effects of coal particle size, coal rank, oxidation temperature and oxygen concentration on the oxidation behavior of coal were investigated. The caking property, FT-IR spectrum and pyrolysis behavior of oxidized sample were measured. In order to clarify the oxidation behavior of coal particle precisely, the differences in chemical structure and caking property between the exterior part and the central part of oxidized coal particle were investigated.

\section{Experimental}

\subsection{Coal Samples}

Eight kinds of coals ranging from bituminous coal to brown coal were used in this study. Table 1 shows characteristics of coal samples. Luscar (Lu), Goonyella (Go) and Pittston-MV (Pi) are highly caking coals and Workworth (Wo), Witbank (Wi) and K-Prima (Kp) are weakly caking coals. Pasil (Pa) and Yallourn (YL), brown coals, were selected to investigate the effect of coal rank on oxidation behaviors. The coal samples were ground and sieved to 2.4- 
Table 1. Proximate and ultimate analysis.

\begin{tabular}{|c|c|c|c|c|c|c|c|c|c|}
\hline \multirow[b]{2}{*}{ COAL } & & \multicolumn{3}{|c|}{ Proximate analysis $[w t \%, d . b]$} & \multicolumn{5}{|c|}{ Ultimate analysis [wt $\%$, d.a.f] } \\
\hline & & ASH & V.M & F.C & C & $\mathrm{H}$ & $\mathrm{N}$ & $\mathrm{S}$ & $\mathrm{O}$ (by diff) \\
\hline Goonyella & (Go) & 8.7 & 24.6 & 66.7 & 90.2 & 5.2 & 1.9 & 0.6 & 2.1 \\
\hline Lusca & (Lu) & 9.5 & 23.5 & 67.0 & 88.3 & 4.6 & 1.5 & 0.3 & 5.3 \\
\hline Pittstonb & $(\mathrm{Pi})$ & 7.3 & 34.3 & 58.4 & 85.7 & 5.5 & 1.6 & 0.9 & 6.3 \\
\hline Workworth & (Wo) & 13.8 & 34.2 & 52.0 & 84.7 & 5.9 & 1.8 & 0.6 & 7.0 \\
\hline Witbank & (Wi) & 7.5 & 32.7 & 59.8 & 85.4 & 5.2 & 2.0 & 0.5 & 6.9 \\
\hline K-Prima & $(\mathrm{Kp})$ & 3.8 & 43.4 & 52.8 & 81.2 & 5.9 & 1.3 & 0.4 & 11.2 \\
\hline Pasil & $(\mathrm{Pa})$ & 2.9 & 47.8 & 49.3 & 73.2 & 5.1 & 1.1 & 0.1 & 20.5 \\
\hline Yallourn & $(\mathrm{YL})$ & 0.9 & 55.2 & 43.9 & 66.1 & 5.3 & 0.6 & 0.3 & 27.7 \\
\hline
\end{tabular}

$4.8,0.5-1.4,0.25-0.5,0.075-0.15$ and $0.045-0.075 \mathrm{~mm}$ and preserved under vacuum condition.

\subsection{Preparation of Samples}

A thermo-balance (Sinkuriko; TGD-9600) and a fixed bed reactor with an electric furnace were used for the oxidation experiments. The fixed bed reactor was made of quartz with $30 \mathrm{~mm}$ inner diameter and $600 \mathrm{~mm}$ length. Coal samples were dried at $107^{\circ} \mathrm{C}$ in an oven or in the thermobalance in nitrogen. After drying, the samples were heated to desired temperature $\left(100-200^{\circ} \mathrm{C}\right)$ at the rate of $30^{\circ} \mathrm{C} /$ $\mathrm{min}$ in the thermo-balance or in the fixed bed reactor in nitrogen. When the temperature reached to the desired temperature, nitrogen gas was switched to mixed gas $(5,10$, $15,20 \mathrm{vol} \%-\mathrm{O}_{2}$ in $\mathrm{N}_{2}$ or $20 \mathrm{vol} \%-\mathrm{CO}_{2}$ in $\mathrm{N}_{2}$ ) and then held for the desired time, $10-400 \mathrm{~min}$. The gases released during the oxidation of coal were measured by Quadra pole Mass spectrometry and GC-FID.

Oxidation experiments were carried out at least two times. The reproducibility of the method was fairy good. For example, the errors observed in TG measurements were within $0.1 \mathrm{mg}$ for the weight change of about $1 \mathrm{mg}$.

The differences in chemical structure and caking property between the exterior part and the central part of coal particle oxidized were investigated. Go coal particles of 2.4$4.8 \mathrm{~mm}$ size were oxidized with $5 \mathrm{vol} \% \mathrm{O}_{2}$ at $200^{\circ} \mathrm{C}$ for $180 \mathrm{~min}$. After the oxidation treatment, using over 200 particles, the exterior parts within the $0.1 \mathrm{~mm}$ thickness at least were recovered by cutting with a knife. The part near the particle center was also recovered by the same way.

To carry out in-situ FT-IR measurements of coal during oxidation, pellets were prepared. The coal samples were ground to $0.045 \mathrm{~mm}$ under and then pressed with 100 $\mathrm{kg} / \mathrm{cm}^{2}$ to make a pellet.

\subsection{Characterization of Oxidized Coal}

The caking property, FT-IR spectrum and pyrolysis behavior of sample were measured. The caking property of sample was evaluated by crucible swelling number (CSN), which was obtained by the standard method (JIS-M8801). Raw or oxidized coal was placed in a crucible and then heated up to $900^{\circ} \mathrm{C}$ by gas burner. CSN was visibly determined by comparison with the standard shape of coke.

FT-IR measurements were carried out to investigate the changes of coal structure and functional groups by oxidation with a FT-IR spectrometer (Nicolet Magna IR 550). The FT-IR spectra were obtained by diffuse reflectance with Kuberuka-Munk unit. The coal sample and $\mathrm{KBr}$ were ground to 0.045 and $0.1 \mathrm{~mm}$ under, respectively, and then

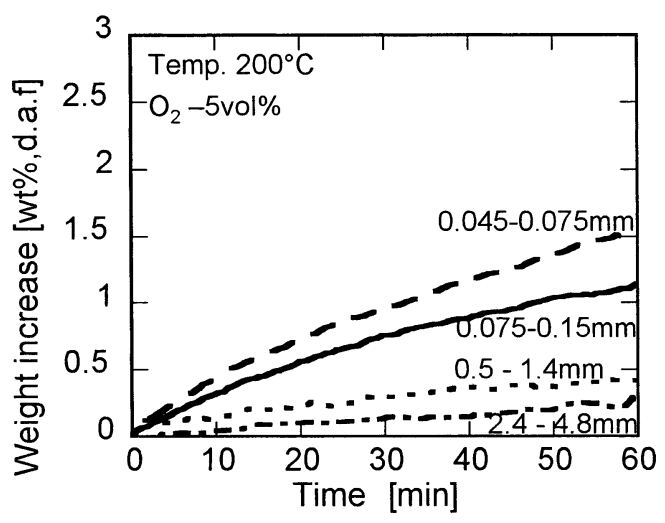

Fig. 1. Absorption profile of oxygen for Go coal.

dried under vacuum condition at $107^{\circ} \mathrm{C}$ for $480 \mathrm{~min}$. After drying, the coal samples were immediately mixed with $\mathrm{KBr}$ (the ratio of coal sample to $\mathrm{KBr}, 0.5: 100$ ), and then the mixture was used for FT-IR measurement. The FT-IR spectra were recorded in the region $400-4000 \mathrm{~cm}^{-1}$. The number of interferograms was fixed at 300 with resolution of $4 \mathrm{~cm}^{-1}$.

Micro reflectance FT-IR analyses were performed on the spectrometer equipped with microscope (IR-plan Advantage-PN0047-xxx) and heating-stage (Japan High tech; TS1500). The pellet (Diameter: $7 \mathrm{~mm}$, Thickness: $2.1 \mathrm{~mm}$ ) was set on the stage, and purged with $20 \mathrm{vol} \% \mathrm{O}_{2}$ in $\mathrm{N}_{2}$ at room temperature. After purging, the sample was heated up to $200^{\circ} \mathrm{C}$ at the rate of $30^{\circ} \mathrm{C} / \mathrm{min}$ and held for $420 \mathrm{~min}$. The FT-IR spectra were scanned at constant intervals.

To investigate the pyrolysis behaviors of raw and oxidized samples, the samples were heated up to $900^{\circ} \mathrm{C}$ at the rate of $30^{\circ} \mathrm{C} / \mathrm{min}$ in nitrogen.

\section{Results and Discussion}

\subsection{Oxidation Behavior}

\subsubsection{Effect of Particle Size}

The oxidation experiments of Go coal samples with various particle sizes ranging from 2.4-4.8, 0.5-1.4, $0.075-0.15$ and $0.045-0.075 \mathrm{~mm}$ were carried out in TG. Figure 1 shows the results obtained at $200^{\circ} \mathrm{C}$ in $5 \mathrm{vol} \%$ of oxygen atmosphere. The increases in weight due to the chemisorption of oxygen during the oxidation were observed for all the samples examined and strongly depended on the coal particle size. When coal is oxidized by oxygen at low temperatures such as below $200^{\circ} \mathrm{C}$, two processes occur concurrently, that is, the weight increases due to the 
chemisorption of oxygen in coal, and the weight decrease due to the release of gaseous products such as $\mathrm{CO}_{2}, \mathrm{CO}$ and water. The decrease in the weight due to the removal of hydrogen is relatively less than that due to the removal of carbon and oxygen. $\mathrm{CO}$ and $\mathrm{CO}_{2}$ gases released during oxidation reaction were measured using the coal particle of $0.045-0.075 \mathrm{~mm}$. In the case of Go coal, total amount of $\mathrm{CO}$ and $\mathrm{CO}_{2}$ released for $60 \mathrm{~min}$ was 0.27 [wt $\%$, d.a.f.] and was considerably less than the increase in the weight observed. We can substantially evaluate the oxidation behavior of Go coal by TG curves.

The oxidation rate of small coal is larger than that of large one. These results show that the oxidation reaction of Go coal is controlled by the rate of internal gaseous diffusion. Similar results were reported by Avison et al., ${ }^{10)}$ Karsner and Perlmutter ${ }^{11)}$ and Mahajan et al. ${ }^{12)}$ On the other hand, Kaji et al. ${ }^{13)}$ reported that the oxidation rate evaluated by $\mathrm{CO}_{2}$ and $\mathrm{CO}$ formation rates during oxidation was not affected by the coal particle size. One of the reasons for the contradiction may be due to used coal rank. The oxidation behavior of coal strongly depends on the coal rank described below.

\subsubsection{Effect of Coal Rank}

Four kinds of coals (Go, Wi, Pa, YL) with different coal rank were used for the oxidation experiments in TG. Figures 2 and $\mathbf{3}$ show the results obtained for Wi coal and $\mathrm{Pa}$ coal under the same oxidation conditions as shown in Fig. 1, respectively. The oxidation profiles depended on the coal rank. The oxidation behaviors of Wi coal are relatively similar to those of Go coal shown in Fig. 1. The increase in weight during oxidation is observed again and the oxidation rate depends on the coal particle size. On the other hand, in the case of Pa coal, lower rank coal, almost no increase in weight in the course of oxidation was observed and the oxidation profile scarcely depended on the particle size. Figure 4 shows the weight change profile of YL coal during the heat treatment and oxidation. In the case of YL coal, the lowest rank coal in this study, the weight of sample gradually decreased during heat treatment at $200^{\circ} \mathrm{C}$. After the $5 \mathrm{vol} \%$ of oxygen was introduced in the TG reactor at $80 \mathrm{~min}$ of treatment time, the weight decrease rate increased. The weight changes observed at 40 min of oxidation time in these oxidation experiments were plotted with carbon contents of raw coals in Fig. 5. The decrease in weight was observed for low rank coal, and the increase in weight was observed for high rank coal. These phenomena may be due to the gas released during oxidation. In the cases of Wi and $\mathrm{Pa}$ coals, total amount of $\mathrm{CO}_{2}$ and $\mathrm{CO}$ released during the oxidation for $60 \mathrm{~min}$ were 0.30 and 0.94 [wt $\%$, d.a.f.], respectively. Judging from that the TG curves of Pa coal during oxidation are almost constant, the corresponding content of oxygen must be incorporated into coal. The decrease in weight observed for YL coal is owing to that the release rate of gaseous products is larger than the uptake rate of oxygen into coal. Differences observed in TG curve may be due to that the oxygen-functional groups formed in low-rank coals are unstable. Further investigations will be needed to clarify the chemical structure of the functional groups in detail.

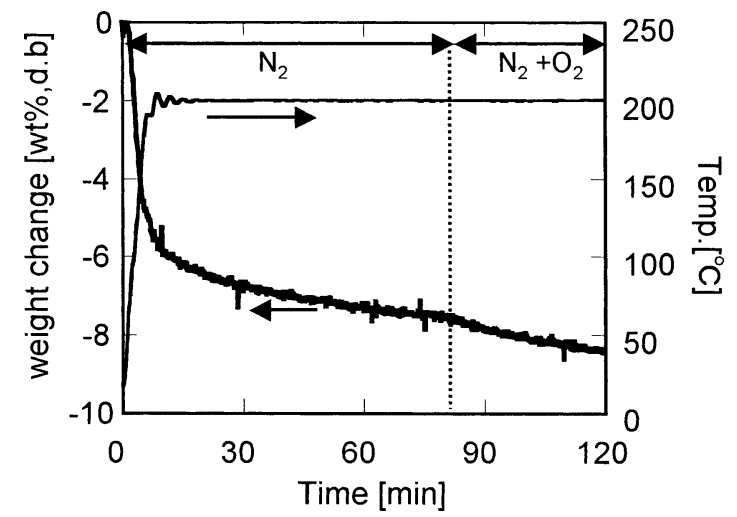

Fig. 4. The weight change profile of YL coal during the heat treatment and oxidation.

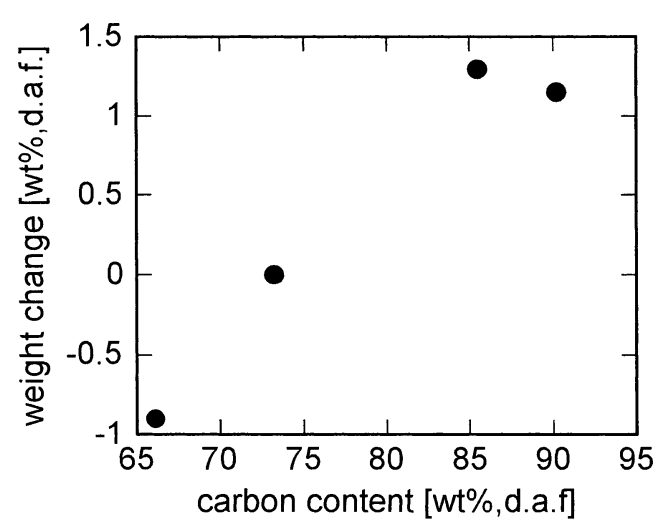

Fig. 5. Relationship between carbon content and weight change.

Fig. 3. Absorption profile of oxygen for Pa coal. 


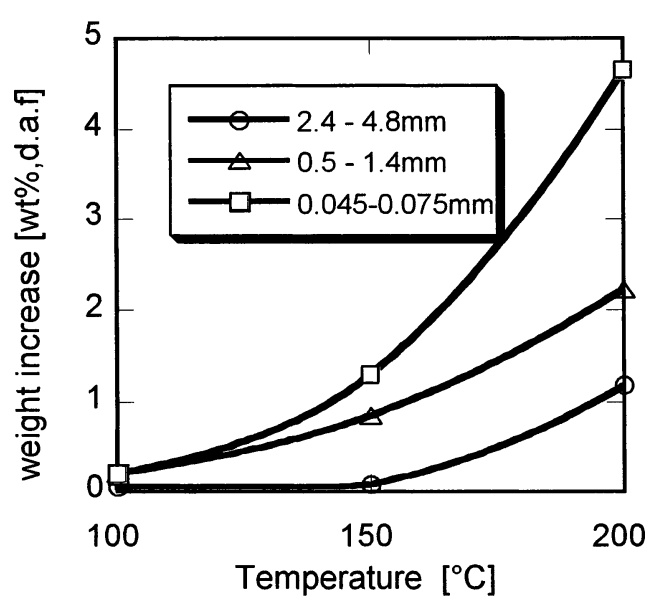

Fig. 6. Absorption profile of oxygen for Lu coal.

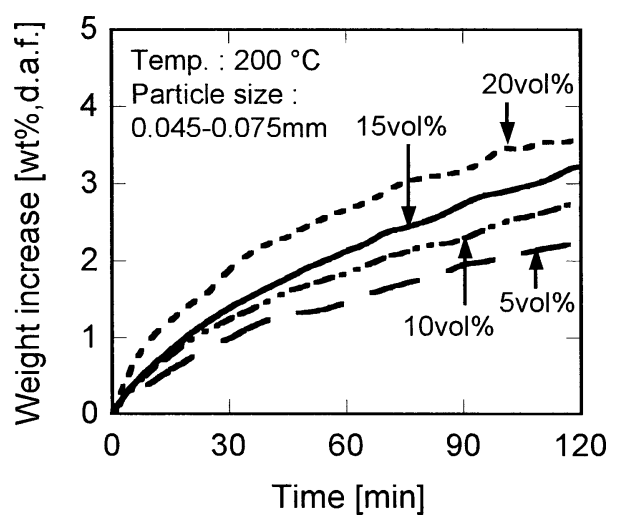

Fig. 7. Effect of $\mathrm{O}_{2}$ concentration on oxidation for Go coal.

\subsubsection{Effects of Temperature and Oxygen Concentration}

Experiments were carried out to examine the effect of oxidation temperature on the oxidation reaction. Figure 6 shows the results obtained at 100,150 and $200^{\circ} \mathrm{C}$. The slight increases in weight are seen at $100^{\circ} \mathrm{C}$ for all particle sizes and much more increases in weight can be seen at 150 and $200^{\circ} \mathrm{C}$.

To investigate the dependence of oxidation concentration, the experiments were carried out in various $\mathrm{O}_{2}$ concentration atmospheres such as $5,10,15$ and $20 \mathrm{vol} \%$ for Go coal. The results are shown in Fig. 7. The increase in weight depended on the $\mathrm{O}_{2}$ concentration. The rate constant and the reaction order were calculated using the unreacted core model by asuuming diffusion through ash layer controls. It was found that the reaction order with respect to oxygen was 0.97 . Kajii et al. ${ }^{13)}$ reported that the oxidation reaction orders with respect to oxygen were 0.5 for $\mathrm{CO}_{2}$ formation and 0.54 for $\mathrm{CO}$ formation, respectively. The observed discrepancy may be due to the difference in used coal type.

\subsection{Characterization of Oxidized Coal}

\subsubsection{Caking Property}

Figure 8 shows the results of CSN measurements for raw Go coal and the samples oxidized at $200^{\circ} \mathrm{C}$ for 30 and $60 \mathrm{~min}$ under various atmospheres. The numbers of raw coal samples were 7-7.5 regardless of the particle size. The caking properties of samples oxidized in oxygen atmosphere lowered and the CSN of oxidized coal strongly de-

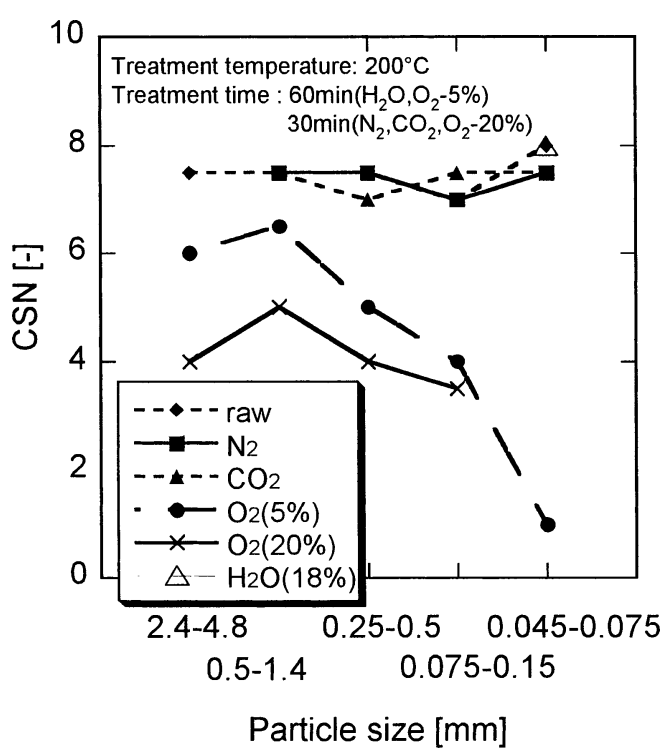

Fig. 8. The change of $\mathrm{CSN}$ with various oxidation treatments for Go coal.

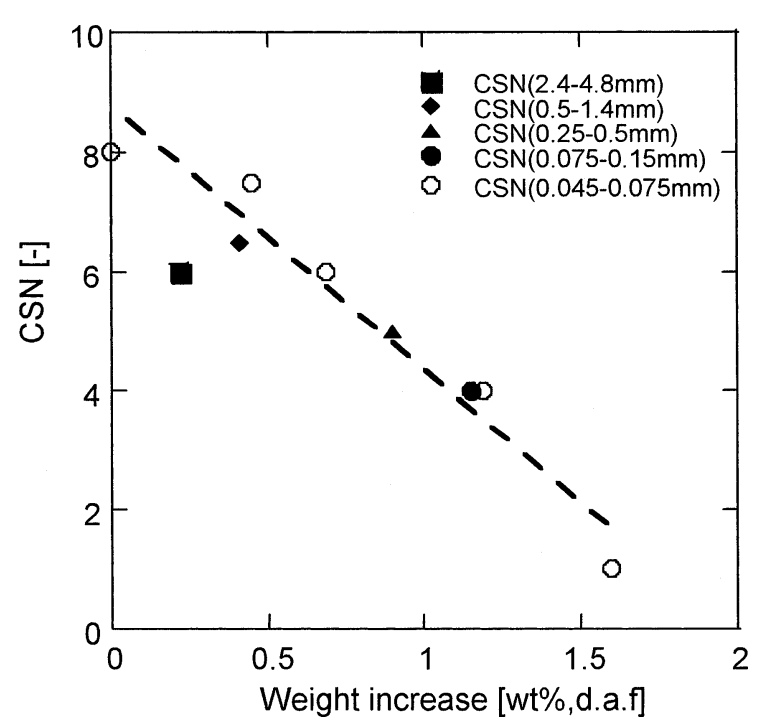

Fig. 9. Relationship between weight increase and CSN.

pended on the coal particle size. For example, the numbers for samples with $2.4-4.8$ and $0.045-0.075 \mathrm{~mm}$ size dropped to 6 and 1, respectively. Figure 9 shows the relation between CSN and the weight gain during the oxidation. The sample used for CSN measurement was oxidized in the fixed bed reactor and the weight gain was obtained from the TG measurement. The oxidation temperature was $200^{\circ} \mathrm{C}$ and $\mathrm{O}_{2}$ concentration was $5 \mathrm{vol} \%$, respectively. The caking properties of oxidized coal may be correlated to the level of oxidation. Maloney et al. ${ }^{14)}$ investigated the caking properties of oxidized coal with $63-75,250-425 \mu \mathrm{m}$ size and reported the similar tendency. In this study, it was found that the caking properties of oxidized coal can be correlated by the level of oxidation regardless of coal particle size. The decaking phenomena of coal by oxidation was already reported by many researchers, ${ }^{1,3,4,7)}$ but the used oxygen concentrations, mainly $20 \mathrm{vol} \%$, were higher than that in this study. From the results obtained in this work, it was revealed that CSN of bituminous coal decreases by the oxidation in the oxidative atmosphere of low oxygen concentra- 


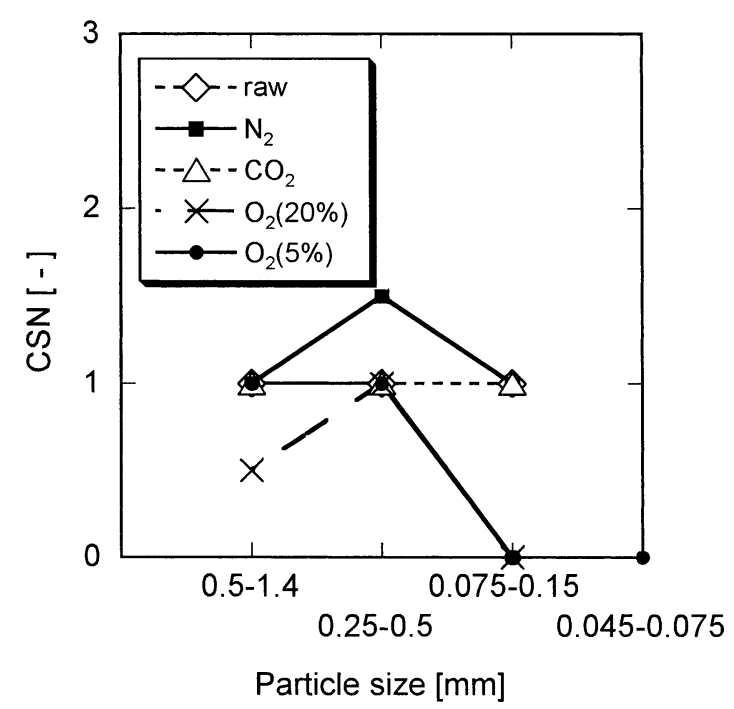

Fig. 10. The change of CSN with various oxidation treatments for Wi coal.

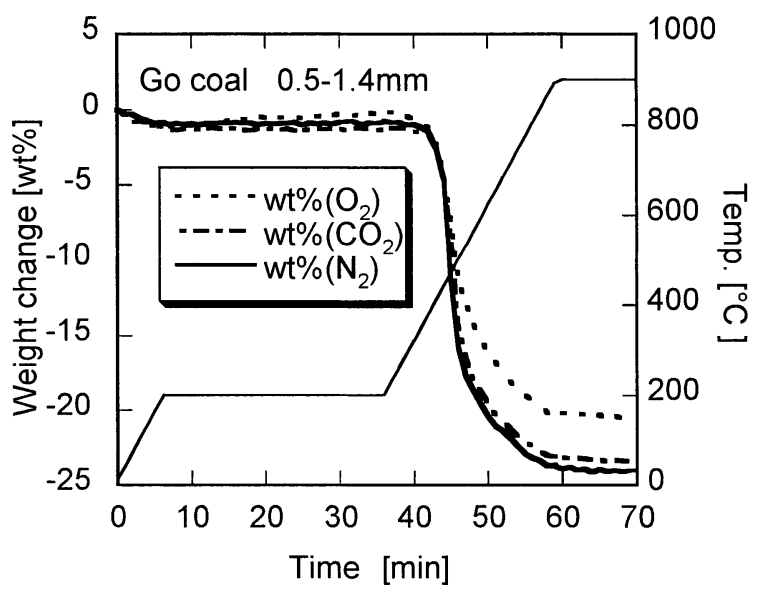

Fig. 11. Pyrolysis behavior of various treated coal.

tion of $5 \mathrm{vol} \%$, which corresponds to that in a flue gas.

Similar experiments were carried out with Wi coal. The results were shown in Fig. 10. The experimental conditions are same as Fig. 8. It was found that caking property of the sample of $0.1 \mathrm{~mm}$ under was completely lost by the oxidation with $5 \mathrm{vol} \% \mathrm{O}_{2}$ at $200^{\circ} \mathrm{C}$ for $60 \mathrm{~min}$.

\subsubsection{Pyrolysis Behavior}

Weight changes during heat-treatment up to $900^{\circ} \mathrm{C}$ in $\mathrm{TG}$ were measured to clarify the effect of low temperature oxidation on the pyrolysis behavior of coal. Figure 11 shows the results obtained for Go coal. The samples were heattreated in $\mathrm{O}_{2}(5 \mathrm{vol} \%), \mathrm{CO}_{2}(20 \mathrm{vol} \%)$ or $\mathrm{N}_{2}$ atmosphere at $200^{\circ} \mathrm{C}$ for $30 \mathrm{~min}$ and then heated up to $900^{\circ} \mathrm{C}$ at the rate of $30^{\circ} \mathrm{C} / \mathrm{min}$ in nitrogen. When Go coal was pretreated in $\mathrm{O}_{2}$ of $5 \mathrm{vol} \%$, the weight loss obviously decreased. Similar phenomenon was reported by Mahajan et al. ${ }^{12)}$ One of the reasons for the decrease in weight loss were attributed to the decrease in the amounts of volatile hydrocarbons due to the release of hydrogen as water during oxidation. In this study, water released during oxidation experiment was not determined. Further study will be needed to clarify the role of hydrogen in coal structure on the pyrolysis behavior of coal.

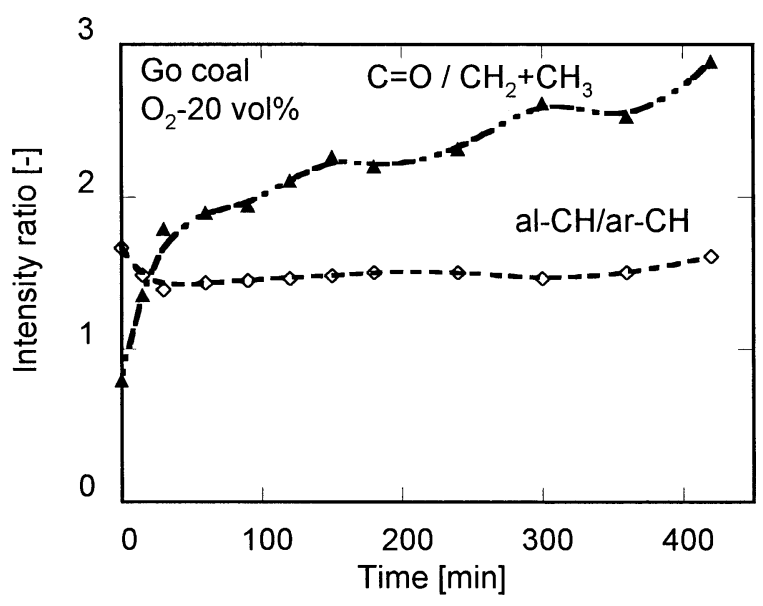

Fig. 12. The changes of surface functional groups during the oxidation.

\subsubsection{FT-IR Analysis}

To investigate the change of coal surface structure during oxidation, the pellet of Go coal was oxidized at $200^{\circ} \mathrm{C}$ under $20 \mathrm{vol} \%-\mathrm{O}_{2}$ atmosphere in the heating stage equipped with FT-IR spectrometer. The remarkable changes of the bands attributable to carbonyl $\left(1710 \mathrm{~cm}^{-1}\right)$ and hydroxyl (3 700-3 $\left.100 \mathrm{~cm}^{-1}\right)$ functional groups were observed. Figure 12 shows the change of the intensity ratios of aliphatic $\mathrm{C}-\mathrm{H}\left(I_{2924 \mathrm{~cm}^{-1}}\right) /$ aromatic $\mathrm{C}-\mathrm{H}\left(I_{3050 \mathrm{~cm}^{-1}}\right)$ and $\mathrm{C}=\mathrm{O}\left(I_{1710 \mathrm{~cm}^{-1}}\right) / \mathrm{CH}_{2}+\mathrm{CH}_{3}\left(I_{1450 \mathrm{~cm}^{-1}}\right)$. The $I_{2924 \mathrm{~cm}^{-1} / I_{3050 \mathrm{~cm}^{-1}}}$

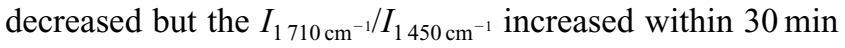
of oxidation time for the contrariety. The oxidation profiles determined by TG measurements shown in Fig. 1 are different from those observed with FT-IR measurements to some extent. That is, the oxidation of coal progressed gradually in TG and the rapid oxidation was observed from FT-IR measurement. This is due to the surface oxidation of sample and the results indicate that the diffusion of oxygen into inner part of coal sample is not so easy. It is considered that the active sites such as aliphatic $\mathrm{C}-\mathrm{H}$ on the surface of coal are oxidized to $\mathrm{C}=\mathrm{O}$ functional groups in advance and then the inner part of coal is oxidized.

In order to investigate the effect of coal rank on the oxidation behavior, six coals were oxidized and characterized with refused reflectance FT-IR analyses. The samples with $0.045-0.075 \mathrm{~mm}$ size were uniformly spread on dishes and heated up to $100-200^{\circ} \mathrm{C}$ under the vacuum condition. When the oven was reached to desired temperature, 20 vol $\%$ of oxygen in nitrogen was introduced and the oxidation was allowed to proceed for $180 \mathrm{~min}$ at atmospheric pressure. Because the oxidized sample was ground for the FT-IR measurements, the information of average structure of coal particle could be obtained. Figure 13 shows the $I_{1710 \mathrm{~cm}^{-1}} / I_{1450 \mathrm{~cm}^{-1}}$ obtained for $180 \mathrm{~min}$ of oxidation time at the temperature range from 20 to $200^{\circ} \mathrm{C}$. When the oxidation temperature increased from 150 to $200^{\circ} \mathrm{C}$, the ratio drastically increased. The increase in the ratio means the formation of carboxyl functional groups. Previous studies $^{4,8)}$ reported that carboxyl functional groups were obviously formed by the oxidation in air at temperatures above $100^{\circ} \mathrm{C}$. The extend of the increase in the ratio strongly depended on the coal rank. The ratios for highly caking coals (Lu, Go, Pi) much more increased than those for weakly 


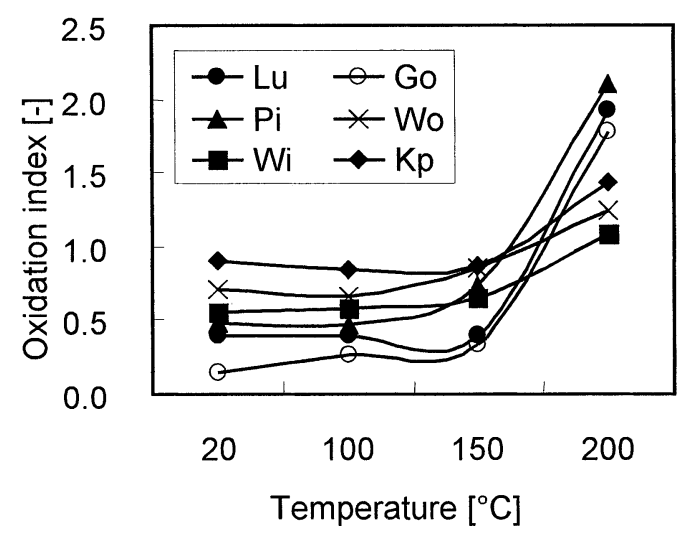

Fig. 13. The change of oxidation index with various conditions.

caking coals (Wo, Wi, Kp). From the obtained data, it is said that the aliphatic $\mathrm{C}-\mathrm{H}$ groups in highly caking coals are easily oxidized during oxidation and remained in coal structure as relatively stable forms.

\subsection{Properties and Chemical Structure of Specified Part in Coal Particle}

The oxidation rates of highly caking coals such as Go and Lu strongly depended on the coal particle size. In this case, because the oxidation reaction is controlled by the rate of internal gaseous diffusion, the chemical structures and some properties of coal may depend on the part in the coal particle. So far, a number of works on the low temperature oxidation of coal were performed and some researchers ${ }^{15-17)}$ reported that the oxidation rate depended on the coal particle size. However, no clear evidence on the difference in chemical structure and properties between exterior part and inner part of coal particle were obtained. In order to get direct information of some properties of specified part in coal particle, the exterior and central parts of oxidized coal particle were characterized.

The caking property of the sample was evaluated by the volume expansion of sample observed after the heat-treatment up to $900^{\circ} \mathrm{C}$ in TG because the amount of prepared sample was too small to measure CSN (JIS-M8801). The pyrolysis experiments were carried out at the rate of $50^{\circ} \mathrm{C} /$ min in the nitrogen. The volume expansions of the raw coal and the center part of oxidized coal particle were about $300 \%$, whereas that of the exterior part was $110 \%$. That is to say, in this experimental condition, the center part of coal is scarcely oxidized and the caking property of the part is substantially similar to that of raw coal.

The devolatilization behaviors of the exterior and the central parts of Go coal are shown in Fig. 14. The experimental condition was same as the pyrolysis experiments described above (The details preparation of coal was described in Sec. 2.2.). The amount of volatile matter for the exterior part was less than that for the central part. It was already shown that the volatile matter of the oxidized coal was less than that of raw coal in Fig. 11. The results shown in Fig. 14 also supported the exterior of the coal particle being oxidized first.

The samples were measured by the FT-IR spectroscopy and the results were displayed in Fig. 15. For the sample of the central part the peaks assigned as aliphatic ether (Al$\mathrm{O}-)$ at $1111 \mathrm{~cm}^{-1}$ and aromatic ether ( $\left.\mathrm{Ar}-\mathrm{O}-\right)$ at 1200

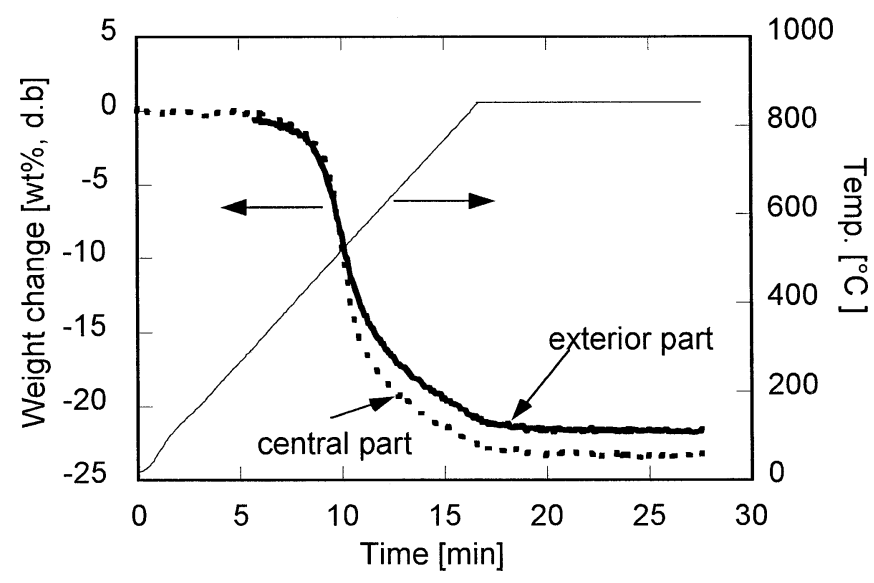

Fig. 14. Pyrolysis behavior of exterior and central part of coal samples.

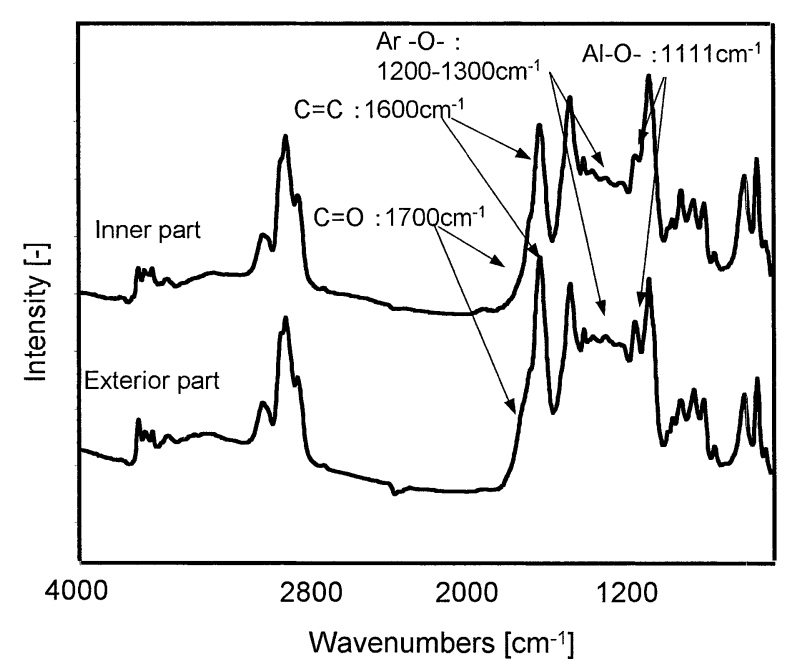

Fig. 15. FT-IR spectra of different parts of oxidized Go coal.

$1300 \mathrm{~cm}^{-1}$ were weak. However, for the outer layer part, both peaks were relatively large and the shoulder peak of carbonyl $(\mathrm{C}=\mathrm{O}$ and $\mathrm{COOH})$ at $1700 \mathrm{~cm}^{-1}$ was more noticeable.

From the results mentioned above, it was concluded that in the case of highly caking coal, the chemical structure and some properties of oxidized coal depended on the position of the coal particle because the mild oxidation reaction of coal proceeded from the exterior part of coal particle. It is suggested that the caking property of caking coal is quite sensitive to the surface structure of coal particle. Maloney et al. ${ }^{14)}$ reported that the plastic properties of an oxidized coal could be partially restored by grinding of the coal in $\mathrm{N}_{2}$ to expose new surface. If the exterior parts of coal oxidized are removed by a commercially feasible method, it is possible to recover high-grade caking coals from oxidized low-grade coals.

\section{Conclusion}

(1) The oxidation reaction of caking coal is controlled by the rate of internal gaseous diffusion.

(2) The caking property of bituminous coal decreases by the oxidation in the oxidative atmosphere of low oxygen concentration of $5 \mathrm{vol} \%$, which corresponds to that in a flue 
gas.

(3) The aliphatic $\mathrm{C}-\mathrm{H}$ groups in highly caking coals are easily oxidized during oxidation and remained in coal structure as relatively stable forms.

In the case of highly caking coal, the chemical structure and some properties of coal oxidized depend on the position of the coal particle because the mild oxidation reaction of coal proceeds from the exterior part of coal particle.

\section{REFERENCES}

1) J. E. Sanchez and J. M. Rincon: Fuel, 76 (1997), 1137.

2) S. V. Pisupati and A. W. Scaroni: Fuel, 72 (1993), 531.

3) H. Seki, O. Ito and M. Iino: Fuel, 69 (1990), 321.

4) H. Seki, O. Ito and M. Iino: Fuel, 69 (1990), 1047.

5) P. C. Painter, R. W. Snyder, D. E. Pearson and J. Kwong: Fuel, 59 (1980), 282.
6) R. Liotta, G. Brons and J. lsaacs: Fuel, 62 (1983), 781.

7) C. A. Rhoads, J. T. Senftle, M. M. Coleman, A. Davis and P. C. Painter: Fuel, 62 (1983), 1387.

8) D. Lopez, Y. Sanada and F. Mondragon: Fuel, 77 (1998), 1623.

9) B. Gong, P. J. Pigram and R. N. Lamb: Fuel, 77 (1998), 1081.

10) N. L. Avison, R. M. Winters and D. D. Perlmutter: AIChE J., 25 (1979), 773.

11) G. G. Karsner, and D. D.Perlmutter: AIChE J., 27 (1981), 920.

12) O. P. Mahajan, M. Komatsu and P. L. Walker, Jr.: Fuel, 59 (1980), 3.

13) R. Kaji, Y. Hishinuma and Y. Nakamura: Fuel, 64 (1985), 297.

14) D. J. Maloney, R. G. Jenkins and P. L. Walker, Jr.: Fuel, 61 (1982), 175.

15) A. Y. Kam, A. N. Hixson and D. D. Perlmutter: Chem. Eng. Sci., 31 (1976), 821.

16) N. L. Avison, R. M. Winters and D. D. Perlmutter: AIChE J., 25 (1979), 773.

17) G. G. Karsner and D. D. Perlmutter: AIChE J., 27 (1981), 920. 